\title{
Evidence for similar principles in episodic and semantic memory: The presidential serial position function
}

\author{
IAN NEATH \\ Memorial University of Newfoundland, St. John's, Newfoundland, Canada
}

\begin{abstract}
When people recall a list of items that they have just experienced (an episodic memory task), the resulting serial position function looks strikingly similar to that observed when people are asked to recall the presidents of the United States (a semantic memory task). Despite the similarity in appearance, there is disagreement about whether the two functions arise from the same processes. A local distinctiveness model of memory, SIMPLE, successfully fit the presidential data using two underlying dimensions: one corresponding to item (or presidential) distinctiveness and the other to order (or positional) distinctiveness. According to the model, presidential primacy and recency are due to the same mechanisms that give rise to primacy and recency effects in both shortand long-term episodic memory. All of these primacy and recency effects reflect the relative distinctiveness principle (Surprenant \& Neath, 2009): Items will be well remembered to the extent that they are more distinct than competing items at the time of retrieval.
\end{abstract}

In most areas of scientific research, there exist laws and principles that are the foundation of research and theory within that discipline. In the domain of human memory, however, there are few principles and no widely accepted laws (Roediger, 2008). One reason offered for the lack of laws and principles is that memory is not a unitary system: Because each memory system has different properties and operates according to different rules, "no profound generalizations can be made about memory as a whole" (Tulving, 1985 , p. 385). In contrast, others have argued that if one views memory from a functional perspective, rather than from a multiple-systems perspective, general principles of memory can be found (Surprenant \& Neath, 2009). The simulation reported here provides an existence proof that the relative distinctiveness principle - items will be well remembered to the extent that they are more distinct than competing items at the time of retrieval-applies equally well to data from short- and long-term episodic memory tasks and to data from semantic memory tasks. As such, it provides further support for the claim that general principles of memory exist and that they apply widely over different time scales, different tests, and different hypothetical underlying memory systems.

\section{Serial Position Functions in Episodic and Semantic Memory}

According to multiple-systems theorists, episodic memory is the system that supports memories of personally experienced events and that enables humans to figuratively travel back in time. In contrast, semantic memory is a separate system that supports memory for decontextualized general knowledge, including facts, concepts, and so forth (Tulving, 2002). One potential problem for this view is the finding that when people recall a list of items that they have just experienced (an episodic memory task), the data look strikingly similar to those observed when people are asked to recall the presidents of the United States (a semantic memory task). In both cases, a characteristic serial position function obtains: Early list items are well recalled (the primacy effect), the last few list items are also well recalled (the recency effect), but midlist items are poorly recalled.

The question is whether episodic and semantic serial position functions have a common underlying cause, and the debate goes back to the modal model or dual store theory of memory. According to this view (e.g., Glanzer, 1972), primacy effects in episodic tasks arise because the first few items gain additional rehearsals and can be transferred from short-term to long-term memory. The recency effect is due to the dumping of items from short-term memory: When the list ends, the last few items remain in short-term memory. The items in the middle have the lowest level of performance because they cannot be rehearsed as much as the first few items and are less likely to be left in short-term memory once list presentation is over. One key piece of evidence taken as support of this explanation is the finding that if recall is delayed $30 \mathrm{sec}$ and rehearsal is prevented, the recency effect disappears, whereas the primacy effect is unaffected (Glanzer \& Cunitz, 1966; Postman \& Phillips, 1965). The reasoning is that the distractor activity that subjects perform during the 30 -sec delay period removes the contents of short-term memory and thus eliminates the recency effect but has no effect on 
information already transferred to long-term memory, and so primacy is preserved.

Presidential serial position effects pose a problem for the standard account, because they suggest that factors other than short- and long-term episodic memory might underlie all serial position functions. In the original presidential recency study, Roediger and Crowder (1976) asked 128 subjects to recall the presidents of the United States by writing down each president's name next to a number. Writing down a correct name in the wrong position counted as an incorrect response. ${ }^{1}$ Roediger and Crowder observed primacy and recency effects similar to those seen in episodic tasks and also noted poor recall of the middle presidents. There was one exception: Recall of Lincoln was significantly higher than that of the surrounding presidents and was seen as an isolation or von Restorff effect. Crowder (1993) reported an updated version that included Carter, Reagan, and Bush with data from 106 students (see Figure 1). Although the general pattern was similar (i.e., pronounced primacy and recency), recall of those presidents who were most recent in 1976 had declined slightly by 1993 .

Roediger and Crowder (1976) stated that "we are strongly inclined to accept the data ... a evidence for a conventional serial position effect in semantic memory" (p. 277) and suggested an explanation based on presidential distinctiveness. The first few and last few presidents are more distinct than middle presidents because of the lack of, or reduced number of, neighbors to one side. Similarly, the high recall of Lincoln is due to additional distinctiveness accruing to his particular place in history. However, Roediger and Crowder noted that the argument is "somewhat circular at the moment, since there is no way to establish distinctive positions ... independently from recall level” (p. 278).
Healy and her colleagues (Healy, Havas, \& Parker, 2000; Healy \& Parker, 2001) argued against this interpretation. In addition to the problem of circularity already noted, Healy et al. pointed out that the argument of Roediger and Crowder (1976) "confuses two uses of the term 'distinctiveness' - referring to both an item characteristic and a position characteristic" (p. 149). Instead, Healy and colleagues (Healy et al., 2000; Healy \& Parker, 2001) argued for different causes of episodic and semantic serial position functions. The standard account of episodic serial position functions was accepted, with contributions from both a short- and a long-term memory system, and semantic serial position functions were thought to be due to differential prior frequency of exposure to order information. For example, students in the United States are frequently told that George Washington was the first president, whereas they are seldom told that Franklin Pierce was the 14th president.

In support of their view, Healy et al. (2000) reported a number of studies, including one in which episodic and semantic serial position functions were directly compared. In the semantic task, the subjects were asked to arrange the names of the presidents into the correct historical order; in the episodic task, the subjects saw a 42-item list of presidential names in a rearranged order and were asked to recall this order. The data were plotted in terms of triplets; that is, performance over three successive positions was averaged. Both the episodic task and the semantic task resulted in serial position functions that showed primacy and recency effects. Healy et al. argued that because the relative levels of primacy and recency differed in the two tasks, there was evidence for different processes. Moreover, they also found that older and younger adults, who

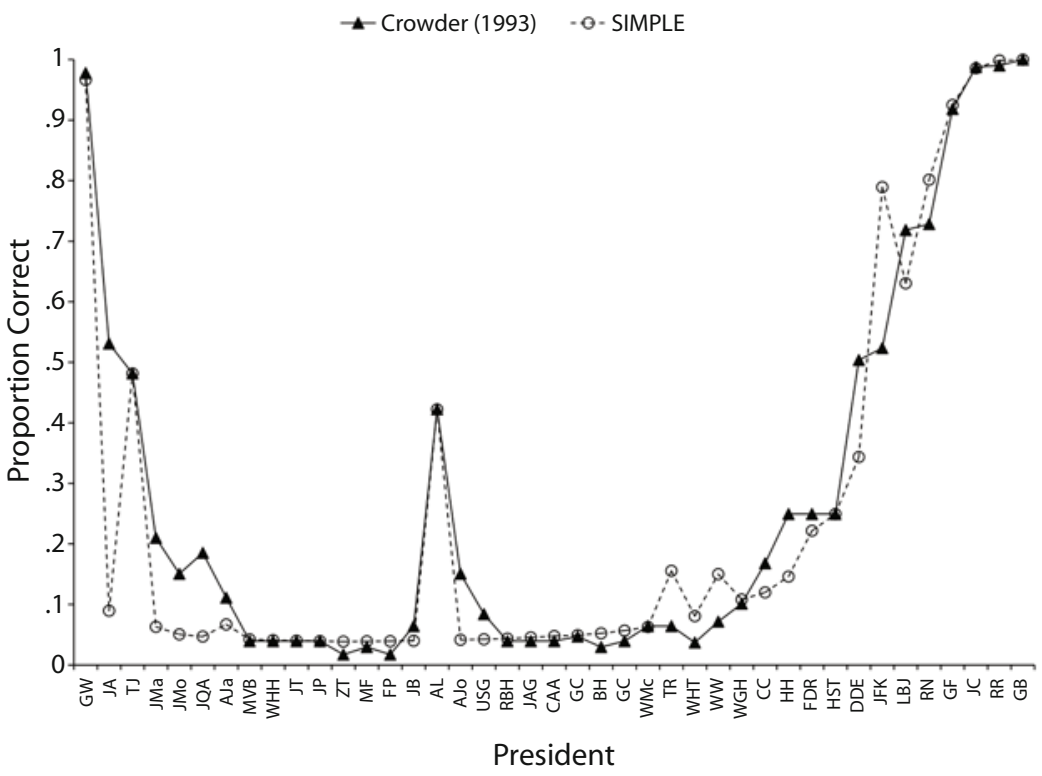

Figure 1. Recall of the presidents of the United States as a function of order in office and the fit of SIMPLE. The data are from "Short-Term Memory: Where Do We Stand?" by R. G. Crowder, 1993, Memory \& Cognition, 21, p. 143. Copyright 1993 by the Psychonomic Society; adapted with permission. The abbreviations represent the U.S. presidents from George Washington (GW) to George H. W. Bush (GB). 
presumably differed in their relative exposure to different presidents, also had different semantic serial position functions.

\section{SIMPLE and Presidential \\ Serial Position Functions}

Surprenant and Neath (2009) proposed seven general principles of memory, one of which is the relative distinctiveness principle: Items will be well remembered to the extent that they are more distinct than competing items at the time of retrieval. Factors at encoding and retrieval combine to determine distinctiveness at the point of the retrieval attempt. According to Surprenant and Neath, this principle underlies all serial position functions (see also Murdock, 1960): Items at the primacy and recency parts of the list tend to be more distinct than middle items, at least in standard memory tests.

One way of thinking about the relative distinctiveness principle is to consider an analogy to telephone poles. As Crowder (1976, p. 462) put it,

The items in a memory list, being presented at a constant rate, pass by with the same regularity as do telephone poles when one is on a moving train. The crucial assumption is that just as each telephone pole in the receding distance becomes less and less distinctive from its neighbors, likewise each item in the memory list becomes less distinctive from the other list items as the presentation episode recedes into the past. Therefore, retrieval probability is being assumed to depend on discriminability of traces from each other.

Several other contemporaneous accounts were also based on this idea (e.g., Baddeley, 1976; Bjork \& Whitten, 1974; Glenberg, Bradley, Kraus, \& Renzaglia, 1983; see Neath $\&$ Brown, 2007, for a review). What they share is the idea that when a person attempts to recall a list of items, the temporally closest items are like the most recent of a line of telephone poles: Just as the last few poles are easy to distinguish from one another visually, the last few items are easy to distinguish from one another in a memory sense. These items are said to be located in a region with few close neighbors. In contrast, items early in the list are hard to discriminate, just like the poles that have receded into the distance. These items are said to be located in a region with more close neighbors. Close neighbors rather than total or distant neighbors are emphasized, because as two poles become further removed from each other, it becomes less likely that one (e.g., Pole 16) will interfere with the perception of the other (e.g., Pole 2).

One way of making the principle more amenable to testing is to instantiate it within a computational model, and Surprenant and Neath (2009) provided a tutorial on how this can be done with a model called SIMPLE (scale independent memory, perception, and learning; G. D. A. Brown, Neath, \& Chater, 2007; Neath \& Brown, 2006, 2007). Here, I sketch out only those aspects relevant to the present simulations.

In SIMPLE, items are represented as points in multidimensional space, and the number and type of dimensions depend on the task. For example, in a typical free recall task, the dimension is time of presentation relative to the time of recall. The reason is that in most cases, the stimuli vary systematically only in terms of when they were presented. It is assumed that physical magnitudes, including temporal values, undergo a log transformation (see Murdock, 1960; Neath, Brown, McCormack, Chater, \& Freeman, 2006). Because of this, a steady rate of presentation (e.g., 1 item per second) results in end items being spaced further apart and beginning items spaced closer together on the temporal dimension, just as in the telephone pole analogy. End items have an additional benefit: By definition, no items precede the first or follow the last items, and this edge effect conveys an additional benefit in making them more discriminable than middle items. Thus, there should be a pronounced recency effect, a smaller primacy effect, and poor recall of interior items. ${ }^{2}$

At the heart of the model, then, is the similarity between representations on the relevant underlying dimensions. The similarity, $\eta_{i, j}$, between two memory representations $i$ and $j$ with values $M_{i}$ and $M_{j}$ on a psychological dimension is given by Equation 1:

$$
\eta_{i, j}=e^{-c\left|M_{i}-M_{j}\right|}
$$

As in many other models, it is assumed that similarity falls off as a decreasing function of the distance between any two representations (Shepard, 1987). The main free parameter in SIMPLE is $c$ : If $c$ is set to a small value, the similarity of two given items will be larger than if $c$ is set to a larger value. Higher values of $c$ correspond to greater distinctiveness (i.e., less influence of more distant items). In some respects, one can think of $c$ like a scaling parameter with larger values resulting in better performance, but the increase in performance is due to a reduction in the influence of near items.

In SIMPLE, the cues for retrieval depend on the task. For example, in an absolute identification experiment, the cue is the test item, and one calculates the probability of producing the appropriate response (e.g., Item 4) given the test item. In tasks using an order dimension, the cue can be thought of as Which was Item 4? More formally, the probability of producing the response associated with item $i, R_{i}$, when given the cue for stimulus $j, C_{j}$, is given by Equation 2, in which $n$ is the number of items in the set:

$$
P\left(R_{i} \mid C_{j}\right)=\frac{\eta_{i, j}}{\sum_{k=1}^{n} \eta_{j, k}} .
$$

People frequently omit responses. One way to induce SIMPLE to omit items is to use a function in which low probabilities (as calculated in Equation 2) are made even lower. So far, a sigmoid function has been used (see G. D. A. Brown et al., 2007, for an extended discussion). Equation 3 shows the implementation, which calculates output probability, $P_{\mathrm{o}}$, based on the estimated recall probability, $P$, from Equation 2:

$$
P_{\mathrm{o}}=\frac{1}{1+e^{-s(P-t)}} .
$$


Parameter $t$ is the threshold, and parameter $s$ is the slope of the transforming function. For example, if $t$ is set to .8 and $s$ is very large, the equation approximates a system that recalls all items with relative values greater than .8 and omits all items with values less than .8. As $s$ becomes smaller, the transition from low to high recall probabilities becomes more gradual.

In many tasks, the stimuli vary systematically not only in terms of when they were presented, but also in terms of selected item characteristics. For example, an experimenter might compare recall of dissimilar- and similarsounding items or of short and long words. In this case, a second dimension is added to SIMPLE. All that needs to be done is to identify the appropriate dimension and obtain each item's value and to adjust Equation 1 to take into account the additional dimension. To address the presidential recency, two dimensions were used, corresponding to the distinction noted by Healy et al. (2000) between item and order distinctiveness.

Because it is not clear how best to measure knowledge of a particular president, a substitute was sought. The number of results returned by a search using Google was taken as a proxy measure, on the assumption that the number of different Web pages on which a president's name appears would be related to both the amount known about that president and his importance. For each president, the search consisted of that president's name in quotes and the word president. ${ }^{3}$ The form of the name that resulted in the most hits was used (i.e., "john f kennedy" president resulted in approximately 6.3 million hits, whereas "john fitzgerald kennedy" president resulted in approximately 500,000 hits). The particular values used in the simulation were obtained on September 30, 2008, and are given in the Appendix.

For the order dimension, the numbers 1, 2, 3, and so on were used. Neath and Crowder (1996) considered orientation - that is, whether the list subjectively begins at the beginning and goes to the end (i.e., currently, Washington would be 1 and Obama 44) or whether the most recent item is considered the first item (i.e., Obama 1 and Washington 44). The latter was used, since this ordering better captures the idea that the current president's position changes more than earlier presidents' positions, receding from a very distinctive position of current to the less distinctive middle portion of the list. It is acknowledged that this is an oversimplification (N. R. Brown, 1990; N. R. Brown \& Siegler, 1991).

When two or more dimensions are combined in SIMPLE, each dimension is weighted such that the sum of the weights is equal to 1 . Equation 1 becomes

$$
\eta_{i, j}=e^{-c\left(W_{O}\left|O_{i}-O_{j}\right|+W_{G}\left|G_{i}-G_{j}\right|\right)},
$$

where $O$ refers to the order dimension, $W_{O}$ is the weight on the order dimension, $G$ is the dimension using Google hits, and $W_{G}$ is the weight on the Google dimension. The values on the order dimension first underwent a log transform, because they are comparable to the physical intensities and are subject - at least to a first approximation - to
Weber's law (G. D. A. Brown et al., 2007; Murdock, 1960). The values on the Google dimension were the raw values scaled to be of the same order of magnitude as the values on the order dimension (i.e., each value was divided by $10,000,000)$. The Google page counts are considered to be a proxy measure for knowledge, and therefore, there was no theoretical rationale for performing a log transformation.

This version of SIMPLE has four free parameters: $c$ is the main parameter and affects how much influence distant items have on a given item, $s$ and $t$ are both used to produce omissions, and $W_{O}$ is the weight on the order dimension. A fifth parameter, the weight on the Google dimension, is given by $W_{G}=1-W_{O}$. Following G. D. A. Brown et al. (2007), fits are described in terms of $r^{2}$. MATLAB was used to find parameter values such that the absolute difference between the observed and predicted values was minimized.

\section{Simulation 1}

For the first simulation, the data reported by Crowder (1993) were fit. There were 41 presidents at the time, so the order dimension went from 1 to 41 . The parameter values used are given in Table 1, and both the data and the fit of the model are shown in Figure 1.

Overall, SIMPLE captures the basic shape of the serial position function well, including the extended recency effect, the shorter primacy effect, and the spike associated with Lincoln. The presidents who are relatively distinct, both by their position (e.g., Washington and Bush) and by their historical status (as measured by Google page results) are recalled more accurately than other presidents. Although the overall fit is good $\left(r^{2}=.913\right)$, there are some deviations. First, predicted recall of John Adams is well below observed levels. One reason is the relatively small number of page hits for Adams (2.4 million). This has the net result of enhancing Washington's relative distinctiveness (who also benefits from having no predecessor), as well as Jefferson's, while reducing that of John Adams. A second deviation is that recall of John F. Kennedy is overpredicted, due primarily to significantly more page hits than there are for the surrounding presidents.

The influence of the item dimension can be readily seen. First, the correlation between Crowder's (1993) data and SIMPLE is $r=.956$, but the correlation between Crowder's (1993) data and the Google page hits is $r=.632$. Similarly, the correlation between SIMPLE and the Google data is

Table 1

Parameters Used to Fit Data Reported by Crowder (1993) in Simulation 1 and by Healy, Havas, and Parker (2000) in Simulation 2 Using Google Page Hits and Familiarity As the Basis for the Item Dimension, Along With a Measure of Fit, $r^{2}$

\begin{tabular}{cccc}
\hline & & \multicolumn{2}{c}{ Healy et al. (2000) } \\
\cline { 3 - 4 } Parameter & Crowder (1993) & Google & Familiarity \\
\hline$c$ & 5.685 & 5.235 & 3.258 \\
$s$ & 13.429 & 13.195 & 11.801 \\
$t$ & .337 & .288 & .624 \\
$W_{O}$ & .730 & .454 & .28 \\
$r^{2}$ & .913 & .960 & .972 \\
\hline
\end{tabular}


$r=.661$, despite the fact that the Google data play an important role in the model. Second, SIMPLE can be run with $W_{O}$ set to 1.0 , eliminating any contribution of Google's data. In this case, SIMPLE produces an almost pure extended recency effect: With the exception of Lincoln, the fit is good from Bush back to Van Buren, but the fit is very poor for Washington to Jackson; overall, $r^{2}=.697$. Clearly, the Google dimension plays an important role and has the largest effects for the distinctive presidents - that is, those presidents such as Washington and Lincoln that stand out from the others. Third, the model can be run with $W_{O}$ set to 0.0 (and thus $W_{G}$ set to 1.0 ) so that the only input to the model is the Google page hit data. The fit is quite poor $\left(r^{2}=.396\right)$, but the correlation between the model and Google page hits is, not surprisingly, nearly perfect at $r=.969$. Thus, both dimensions are necessary, and performance reflects a combination of the two.

\section{Simulation 2}

Healy et al. (2000, Experiment 1) had 24 subjects recall 42 presidents, but otherwise, their study is comparable to that of Crowder (1993). Healy et al. reported their data in terms of triplets. SIMPLE was fit to these data by first predicting recall of 42 presidents (one more than in Simulation 1) and then averaging the predicted recall to produce comparable triplets. The parameters are shown in Table 1, and the data and the fit of SIMPLE are shown in Figure 2A.

Again, SIMPLE fit the overall pattern well, with extended recency and a shorter primacy effect. The sole apparent deviation of the model from the data is overpredicting recall of the triplet containing Lincoln, but despite the large visual discrepancy, $r^{2}=.960$. For comparison purposes, the data of Crowder (1993) and the predicted results from Simulation 1 were also converted to triplets, and $r^{2}=.972$. One difference is the weight given to the two dimensions. In Simulation $1, W_{O}=.730$, whereas here, $W_{O}=.454$. This is due primarily to fitting 41 positions versus just 14 .

Healy et al. (2000) asked their subjects to indicate, on a scale of $1-6$, how familiar they were with each president. These rating data offer a way independent of Google searches to quantify the item dimension. ${ }^{4}$ This simulation was identical to the previous ones, except that the item dimension consisted of ratings rather than page hits. The results are shown in Figure 2B, and the parameter values are given in Table 1. The major difference is that the prediction for Lincoln is now more accurate. The fit is slightly better using familiarity than using Google page hits, with $r^{2}=.987$ versus .972 (RMSD $=.025$ and .035 , respectively), but it is likely premature to make much of this small difference. However, collecting familiarity ratings and other similar data might prove profitable in future research in explicating differences among subject populations and subsequent performance.

\section{Discussion}

The serial position function observed when people are asked to recall the presidents of the United States (a semantic memory task) is similar in appearance to serial position functions observed in tasks that tap episodic memory. SIMPLE was developed initially to account for episodic memory, regardless of the time scale, whether sensory memory, short-term memory, or long-term memory. In the case of episodic tasks, the application of the model was the same: Items are represented in terms of their time of presentation relative to the time of retrieval. The serial position function arises because items toward the end of the list are like near telephone poles: They have few close neighbors and so are easier to discriminate from one another. Items toward the beginning of the list are like more distant telephone poles: They appear closer together and therefore have more close neighbors. In addition, the first and last items benefit from edge effects (the absence of a neighbor on one side).

For episodic memory tasks, it is appropriate to use the time of presentation relative to the time of retrieval, because all of the items are directly experienced by the subjects and because the experimenter has typically removed most or all other sources of systematic variation. For semantic memory tasks, however, having time as the primary dimension is not reasonable. Instead of order being represented on a temporal dimension, it is represented on a positional dimension. Other than this change in the underlying dimension, the model works the same in the two cases. For example, Surprenant, Neath, and Brown (2006) fit SIMPLE to an episodic memory task involving recall of dissimilar- and similarsounding items. In addition to the main dimension, they used one based on measured confusability of the to-beremembered items to reflect the difference between the similar and dissimilar letters. Analogously, the present simulations used a second dimension to capture item distinctiveness, for which both Google page hits and familiarity ratings served. This second dimension modulated the basic shape of the serial position function for certain presidents, just as Surprenant et al.'s confusability dimension modulated the basic shape of the serial position function for certain letters.

It is important to remember that although the claim is that serial position functions in episodic and semantic memory can both be explained by the relative distinctiveness hypothesis and can both be fit by SIMPLE, this does not mean that a given manipulation must affect the two systems in the same way. Consider the following example. Suppose that the list of to-be-remembered items consists of the names of the presidents of the United States. In the episodic case, each item is shown in random order for $1 \mathrm{sec}$. In the control condition, the end of the list is followed immediately by the memory test. In the experimental condition, the test is delayed by $30 \mathrm{sec}$ of distracting (but not interfering) activity. We know that this manipulation will remove the recency effect (Glanzer \& Cunitz, 1966; Postman \& Phillips, 1965). According to SIMPLE, this occurs because the items are represented on a temporal dimension. In the control condition, the last few items are like the nearest in a line of telephone poles that have yet to recede into the distance. In the experimental condition, however, the $30 \mathrm{sec}$ of distractor activity compresses these items, making them more like telephone poles in the 
A

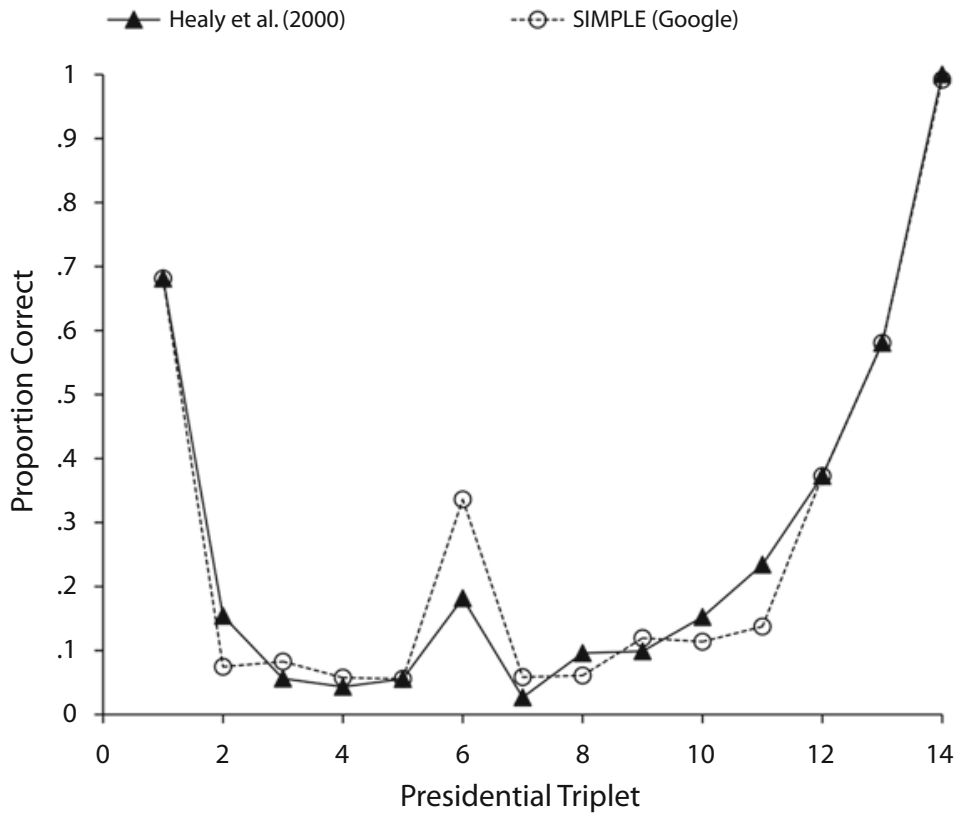

B

$\neg$ - Healy et al. (2000)

-๑-- SIMPLE (Familiarity)

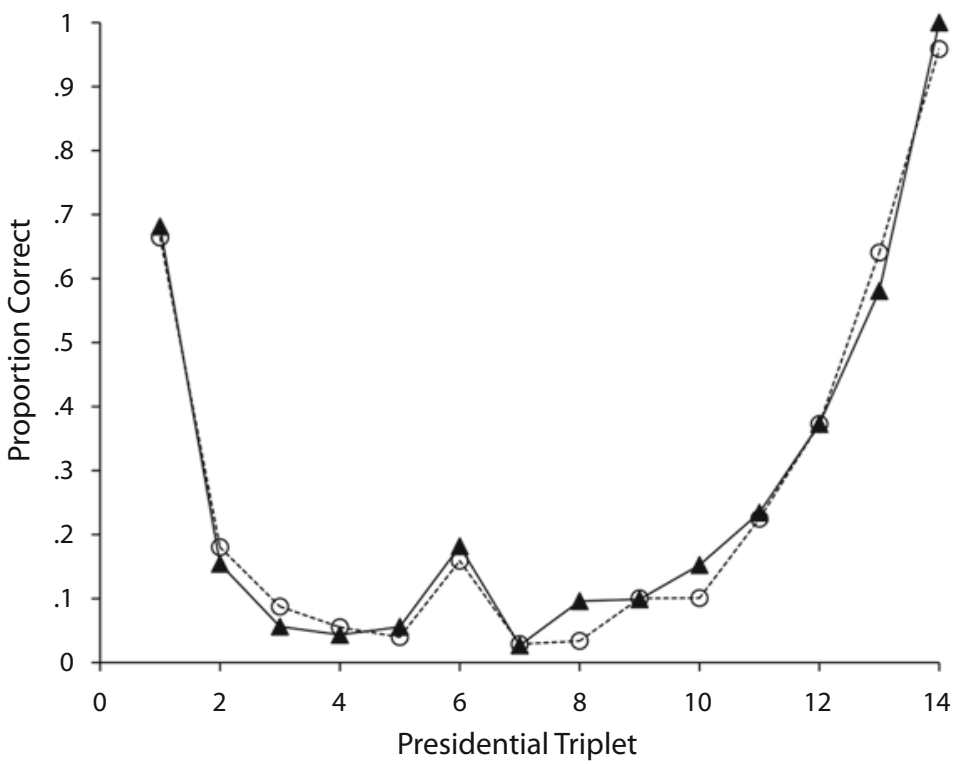

Figure 2. Recall of the presidents of the United States as a function of triplet position and the fit of SIMPLE when Google page hits (A) and familiarity ratings $(B)$ are used as the basis for the item dimension. The data are from "Comparing Serial Position Effects in Semantic and Episodic Memory Using Reconstruction of Order Tasks," by A. F. Healy, D. A. Havas, and J. T. Parker, 2000, Journal of Memory and Language, 42, pp. 147-167. Copyright 2000 by Elsevier. Reprinted with permission.

middle distance (see the simulation on p. 548 of G. D. A. Brown et al., 2007). In the semantic task, however, the situation is different: A control group is asked to recall the presidents and is then allowed to begin immediately. The experimental group is asked to recall the presidents but is delayed from beginning for $30 \mathrm{sec}$. SIMPLE predicts no difference, because the presidents are represented on a positional-not temporal-dimension.

In the episodic memory literature, serial position functions observed in short-term settings and those observed in long-term settings were thought to differ. SIMPLE fits both types of settings using the same underlying dimen- 
sion: the relative time between the presentation (or last rehearsal of the item; cf. Tan \& Ward, 2000) and the time of retrieval (see G. D. A. Brown et al., 2007; Neath \& Brown, 2006). Similarly, serial position functions observed with free and serial recall were long considered to be quite different, requiring models devoted to just one task or the other. Again, SIMPLE offers the same basic explanation for the two types of recall. Although there are differences to be observed between serial and free recall, G. D. A. Brown, Chater, and Neath (2008; see also Bhatarah, Ward, Smith, \& Hayes, 2009) argued that these apparent differences result from task demands (i.e., tending to output the last few items first in free recall but having to recall the first item first in serial recall), the tendency to use shorter lists for serial recall and longer lists for free recall, and the involvement of rehearsal processes, to name only a few. ${ }^{5}$

A similar argument can be made for episodic versus semantic memory: The basic explanation is the same in the two tasks, and the same principle applies to the two memory systems, but there are some differences that arise from the nature of the task. In the episodic task, a temporal dimension is used, whereas in the semantic task, a position dimension is used instead. The point is that although the underlying dimensions differ, the principles are the same.

\section{Conclusions}

Roediger and Crowder (1976, p. 277) noted their "strong preference" to conclude that "episodic and semantic memory serial position functions reflect a common mechanism." The simulations reported here provide an existence proof that a model developed to account for episodic serial position functions can use the same processes to account for semantic serial position functions: Items that have more close neighbors in psychological space at the time of retrieval are less likely to be remembered than items with fewer close neighbors. SIMPLE can be seen as an instantiation of this relative distinctiveness principle, which is invoked as an explanation for serial position functions, regardless of whether the task is thought to tap iconic memory, short-term memory, long-term memory, or semantic memory. As such, it provides further support for a view of memory in which there exist general principles that apply widely over different time scales, different tests, and different hypothetical underlying memory systems (Surprenant \& Neath, 2009).

\section{AUTHOR NOTE}

This work was supported, in part, by a grant from NSERC. I thank A. F. Healy, H. L. Roediger III, and A. M. Surprenant for comments on an earlier version. Correspondence concerning this article should be addressed to I. Neath, Department of Psychology, Memorial University of Newfoundland, St. John's, NL, A1B 3X9 Canada (e-mail: ineath@ mun.ca).

\section{REFERENCES}

Baddeley, A. D. (1976). The psychology of memory. New York: Basic Books.

Bhatarah, P., Ward, G., Smith, J., \& Hayes, L. (2009). Examining the relationship between free recall and immediate serial recall: Similar pat- terns of rehearsal and similar effects of word length, presentation rate, and articulatory suppression. Memory \& Cognition, 37, 689-713.

BJoRK, R. A., \& WhitTEN, W. B. (1974). Recency-sensitive retrieval processes in long-term free recall. Cognitive Psychology, 6, 173-189.

Brown, G. D. A., Chater, N., \& Neath, I. (2008). Serial and free recall: Common effects and common mechanisms? A reply to Murdock (2008). Psychological Review, 115, 781-785.

Brown, G. D. A., Neath, I., \& Chater, N. (2007). A temporal ratio model of memory. Psychological Review, 114, 539-576.

BRown, N. R. (1990). Organization of public events in long-term memory. Journal of Experimental Psychology: General, 119, 297-314.

BRown, N. R., \& SiEgLER, R. S. (1991). Subjective organization of U.S. presidents. American Journal of Psychology, 104, 1-33.

Crowder, R. G. (1976). Principles of learning and memory. Hillsdale, NJ: Erlbaum.

Crowder, R. G. (1993). Short-term memory: Where do we stand? Memory \& Cognition, 21, 142-145.

Glanzer, M. (1972). Storage mechanisms in recall. In G. H. Bower (Ed.), The psychology of learning and motivation (Vol. 5, pp. 129153). New York: Academic Press.

Glanzer, M., \& Cunitz, A. R. (1966). Two storage mechanisms in free recall. Journal of Verbal Learning \& Verbal Behavior, 5, 351-360.

Glenberg, A. M., Bradley, M. M., Kraus, T. A., \& Renzaglia, G. J. (1983). Studies of the long-term recency effect: Support for a contextually guided retrieval hypothesis. Journal of Experimental Psychology: Learning, Memory, \& Cognition, 9, 231-255.

Healy, A. F., Havas, D. A., \& Parker, J. T. (2000). Comparing serial position effects in semantic and episodic memory using reconstruction of order tasks. Journal of Memory \& Language, 42, 147-167.

Healy, A. F., \& Parker, J. T. (2001). Serial position effects in semantic memory: Reconstructing the order of U. S. presidents and vice presidents. In H. L. Roediger III, J. S. Nairne, I. Neath, \& A. M. Surprenant (Eds.), The nature of remembering: Essays in honor of Robert $G$. Crowder (pp. 171-188). Washington, DC: American Psychological Association.

LeWANDOWSKy, S., \& BRown, G. D. A. (2005). Serial recall and presentation schedule: A micro-analysis of local distinctiveness. Memory, 13, 283-292.

Lewandowsky, S., Brown, G. D. A., Wright, T., \& Nimmo, L. M. (2006). Timeless memory: Evidence against temporal distinctiveness models of short-term memory for serial order. Journal of Memory \& Language, 54, 20-38.

Murdock, B. B., JR. (1960). The distinctiveness of stimuli. Psychological Review, 67, 16-31.

Neath, I., \& Brown, G. D. A. (2006). SIMPLE: Further applications of a local distinctiveness model of memory. In B. H. Ross (Ed.), The psychology of learning and motivation (Vol. 46, pp. 201-243). San Diego: Academic Press.

Neath, I., \& Brown, G. D. A. (2007). Making distinctiveness models of memory distinct. In J. S. Nairne (Ed.), The foundations of remembering: Essays in honor of Henry L. Roediger III (pp. 125-140). New York: Psychology Press.

Neath, I., Brown, G. D. A., McCormack, T., Chater, N., \& FreeMAN, R. (2006). Distinctiveness models of memory and absolute identification: Evidence for local, not global, effects. Quarterly Journal of Experimental Psychology, 59, 121-135.

NeAth, I., \& Crowder, R. G. (1996). Distinctiveness and very shortterm serial position effects. Memory, 4, 225-242.

Postman, L., \& Phillips, L. W. (1965). Short-term temporal changes in free recall. Quarterly Journal of Experimental Psychology, 17, 132138.

RoEDIGER, H. L., III (2008). Relativity of remembering: Why the laws of memory vanished. Annual Review of Psychology, 59, 225-254.

Roediger, H. L., III, \& Crowder, R. G. (1976). A serial position effect in recall of United States presidents. Bulletin of the Psychonomic Society, 8, 275-278.

SHEPARD, R. N. (1987). Toward a universal law of generalization for psychological science. Science, 237, 1317-1323.

Surprenant, A. M., \& Neath, I. (2009). Principles of memory. New York: Psychology Press.

Surprenant, A. M., Neath, I., \& Brown, G. D. A. (2006). Modeling age-related differences in immediate memory using SIMPLE. Journal of Memory \& Language, 55, 572-586. 
TAN, L., \& WARD, G. (2000). A recency-based account of the primacy effect in free recall. Journal of Experimental Psychology: Learning, Memory, \& Cognition, 26, 1589-1625.

Tulving, E. (1985). How many memory systems are there? American Psychologist, 40, 385-398.

Tulving, E. (2002). Episodic memory: From mind to brain. Annual Review of Psychology, 53, 1-25.

\section{NOTES}

1. For a discussion of scoring issues (e.g., the nonconsecutive terms of Grover Cleveland, presidents with the same last name, etc.) see Roediger and Crowder (1976) and Healy, Havas, and Parker (2000).
2. Of course, this assumes an absence of any of the numerous manipulations that can affect the shape of the serial position function.

3. For President George H. W. Bush, the search term was modified to exclude pages that refer to President George W. Bush: president "george bush" - "george w bush"

4. I thank Alice Healy for this suggestion.

5. There is some debate about whether a temporal dimension is used in all episodic tasks. Lewandowsky and colleagues (e.g., Lewandowsky \& Brown, 2005; Lewandowsky, Brown, Wright, \& Nimmo, 2006) have argued that certain immediate serial recall tasks use a positional dimension. When directly compared, the predictions of the temporal and positional versions of SIMPLE for such tasks are quite similar (e.g., Surprenant et al., 2006).

\section{APPENDIX}

\begin{tabular}{|c|c|c|c|}
\hline Order & Name & Term & Google Results \\
\hline 1 & George Washington & $1789-1797$ & $19,300,000$ \\
\hline 2 & John Adams & $1797-1801$ & $2,480,000$ \\
\hline 3 & Thomas Jefferson & 1801-1809 & $11,600,000$ \\
\hline 4 & James Madison & $1809-1817$ & $1,910,000$ \\
\hline 5 & James Monroe & $1817-1825$ & 585,000 \\
\hline 6 & John Quincy Adams & $1825-1829$ & 705,000 \\
\hline 7 & Andrew Jackson & $1829-1837$ & $3,600,000$ \\
\hline 8 & Martin Van Buren & $1837-1841$ & 350,000 \\
\hline 9 & William Henry Harrison & $1841-1841$ & 245,000 \\
\hline 10 & John Tyler & $1841-1845$ & 762,000 \\
\hline 11 & James Knox Polk & $1845-1849$ & 191,000 \\
\hline 12 & Zachary Taylor & $1849-1850$ & 591,000 \\
\hline 13 & Millard Fillmore & $1850-1853$ & 223,000 \\
\hline 14 & Franklin Pierce & $1853-1857$ & 311,000 \\
\hline 15 & James Buchanan & $1857-1861$ & 443,000 \\
\hline 16 & Abraham Lincoln & $1861-1865$ & $11,400,000$ \\
\hline 17 & Andrew Johnson & $1865-1869$ & 558,000 \\
\hline 18 & Ulysses S. Grant & $1869-1877$ & 622,000 \\
\hline 19 & Rutherford B. Hayes & $1877-1881$ & 226,000 \\
\hline 20 & James A. Garfield & $1881-1881$ & 134,000 \\
\hline 21 & Chester A. Arthur & $1881-1885$ & 113,000 \\
\hline 22 & Grover Cleveland & 1885-1889 & 616,000 \\
\hline 23 & Benjamin Harrison & $1889-1893$ & 386,000 \\
\hline 24 & Grover Cleveland & 1893-1897 & 616,000 \\
\hline 25 & William McKinley & 1897-1901 & 511,000 \\
\hline 26 & Theodore Roosevelt & 1901-1909 & $4,940,000$ \\
\hline 27 & William Howard Taft & 1909-1913 & 365,000 \\
\hline 28 & Woodrow Wilson & $1913-1921$ & $3,880,000$ \\
\hline 29 & Warren G. Harding & $1921-1923$ & 205,000 \\
\hline 30 & Calvin Coolidge & $1923-1929$ & 659,000 \\
\hline 31 & Herbert Hoover & 1929-1933 & 919,000 \\
\hline 32 & Franklin Roosevelt & $1933-1945$ & $2,740,000$ \\
\hline 33 & Harry S Truman & $1945-1953$ & $1,900,000$ \\
\hline 34 & Dwight D. Eisenhower & 1953-1961 & 905,000 \\
\hline 35 & John F. Kennedy & $1961-1963$ & $6,370,000$ \\
\hline 36 & Lyndon B. Johnson & 1963-1969 & $1,380,000$ \\
\hline 37 & Richard M. Nixon & 1969-1974 & $3,010,000$ \\
\hline 38 & Gerald R. Ford & 1974-1977 & $1,260,000$ \\
\hline 39 & Jimmy Carter & $1977-1981$ & $4,020,000$ \\
\hline 40 & Ronald Reagan & 1981-1989 & $6,030,000$ \\
\hline 41 & George H. W. Bush & 1989-1993 & $12,500,000$ \\
\hline 42 & Bill Clinton & 1993-2001 & $22,500,000$ \\
\hline
\end{tabular}

(Manuscript received November 6, 2009; revision accepted for publication December 11, 2009.) 